\title{
Epinephrine Use during Newborn Resuscitation
}

\author{
Vishal S. Kapadia* and Myra H. Wyckoff \\ Pediatrics, University of Texas Southwestern Medical Center, Dallas, TX, USA
}

Epinephrine use in the delivery room for resuscitation of the newborn is associated with significant morbidity and mortality. Evidence for optimal dose, timing, and route of administration of epinephrine during neonatal resuscitation comes largely from extrapolated adult or animal literature. In this review, we provide the current recommendations for use of epinephrine during neonatal resuscitation and also the evidence behind these recommendations. In addition, we review the current proposed mechanism of action of epinephrine during neonatal resuscitation, review its adverse effects, and identify gaps in knowledge requiring urgent research.

Keywords: epinephrine, neonatal resuscitation, asphyxia, newborn, delivery room, infants

\section{OPEN ACCESS}

Edited by:

Graeme R. Polglase,

Monash University, Australia

Reviewed by: Elizabeth Foglia,

Children's Hospital of

Philadelphia, USA

Georg Schmolzer,

University of Alberta, Canada

${ }^{*}$ Correspondence:

Vishal S. Kapadia

vishal.kapadia@utsouthwestern.edu

Specialty section:

This article was submitted

to Neonatology,

a section of the journal

Frontiers in Pediatrics

Received: 10 January 2017

Accepted: 13 April 2017

Published: 01 May 2017

Citation:

Kapadia VS and Wyckoff MH (2017) Epinephrine Use during

Newborn Resuscitation.

Front. Pediatr. 5:97.

doi: 10.3389/fped.2017.00097

\section{INTRODUCTION}

Approximately $10 \%$ of newborns require some assistance to begin breathing at birth (1). Majority of these newborns improve without the need for cardiac compression or epinephrine if skillful positive-pressure ventilation is initiated in a timely manner. Less than $0.1 \%$ of all newborns require epinephrine, making epinephrine use in delivery room neonatal resuscitation an uncommon event $(2,3)$. Newborns who do require extensive cardiopulmonary resuscitation (CPR) including epinephrine have a high incidence of mortality. Those who survive frequently suffer from poor longterm neurodevelopmental outcomes (4-7).

The majority of recommendations regarding indication, dose, and route of administration of epinephrine in the delivery room are based on extrapolations from adult and animal studies. The infrequent use of epinephrine in the delivery room and ethical dilemmas in designing a clinical trial for examining the role of epinephrine during neonatal resuscitations make it very difficult to obtain high levels of evidence for recommendations regarding epinephrine use during neonatal resuscitation. Many of the animal and adult data come from a non-perfusion ventricular fibrillation arrest, which is not the pathophysiology of a newborn in the delivery room who suffers from an asphyxial arrest. Another major limitation of extrapolation from these studies is that newborns in the delivery room have unique transitional physiology including fluid-filled alveoli, an open ductus arteriosus, and high pulmonary pressures with limited pulmonary blood flow. Newly born infants must transition from fetal to newborn circulation. In the era of evidence-based medicine, due to lack of rigorous scientific evidence, proper use of epinephrine including dose and route of administration remains controversial. Even though epinephrine is not commonly needed in neonatal resuscitation, its association with death and poor prognosis raises questions as to whether optimization of epinephrine use and dosing, specifically tailored to the unique circumstances of the newly born infant, could improve outcomes.

This review aims to describe current recommendations for epinephrine use in neonatal resuscitation, the evidence behind such recommendations, and the critical knowledge gaps. 


\section{HISTORY OF EPINEPHRINE USE IN NEONATAL RESUSCITATION}

Epinephrine is the only medication recommended during neonatal resuscitation in the delivery room $(8,9)$. Naloxone, sodium bicarbonate, and other vasopressors are currently not considered a part of acute resuscitation but can be used postresuscitation for special circumstances (9-11).

Management of the airway and assisted ventilation of the newborn baby can be found in ancient texts dating back to the Old Testament of the Bible, the Talmud, and Hippocrates $(12,13)$. However, reports of medication use in neonatal resuscitation can only be found after the early 1950s with the evolution of modern neonatology $(13,14)$. George Oliver and Edward Schaffer in 1893 first showed that adrenal glands contained a substance with distinct pharmacological properties $(14,15)$. It is a naturally occurring catecholamine produced by chromaffin cells at the adrenal medulla and stored in chromaffin granules. In 1897, John Abel in the United States prepared crude adrenal extracts and called them epinephrine (16). Epinephrine was used first time in pulseless patients in around 1906 by Crile and Dolley (17). Its resuscitative properties were further investigated by Wiggers in the 1930s and Redding and Pearson in the 1960s $(18,19)$.

\section{HEMODYNAMIC EFFECTS OF EPINEPHRINE}

Epinephrine stimulates all four adrenergic receptors $\left(\alpha_{1}, \alpha_{2}, \beta_{1}\right.$, and $\beta_{2}$ ) in vivo. When looked at in isolation, stimulation of the different adrenergic receptors by epinephrine results in different and sometimes opposing effects. It causes peripheral vasoconstriction via stimulation of $\alpha_{1}$ receptors in vascular smooth muscle cells. By stimulating $\beta 1$ receptors in the myocardium, it causes chronotropy (increased heart rate), inotropy (increased contractility), dromotropy (increase conduction velocity), and lusitropy (increased rate of myocardial relaxation) (10, 20-22). Stimulation of $\alpha_{2}$ receptors leads to presynaptic inhibition of nor-epinephrine release in the central nervous system and vasoconstriction of coronary arteries. Through $\beta_{2}$ receptor stimulation, it causes vascular smooth muscle relaxation and increased myocardial contractility, but these effects are usually minor. In vivo effects of epinephrine depend on the dose of epinephrine, number of receptors available on target tissues, the affinity of these receptors, and local target tissue environments (23).

\section{MECHANISM OF ACTION DURING CPR}

Initially it was believed that epinephrine causes return of spontaneous circulation (ROSC) in cardiac arrest via its myocardial stimulant effects ( $\beta$ adrenergic effects: chronotropic and inotropic) (10). In the 1960s, Redding demonstrated in dogs that the pure $\alpha$-agonist, methoxamine, was as effective as epinephrine in achieving ROSC during CPR, whereas the pure $\beta$-agonist, isoproterenol, was no more effective than CPR alone (19). Otto et al. who used pretreatment with $\alpha$-adrenergic blockade (phenoxybenzamine) and $\beta$-adrenergic blockade (propranolol) before infusing epinephrine confirmed that $\alpha$-adrenergic stimulation is the most important action of epinephrine for ROSC in CPR (24).

It is now established that the most reliable method for determining the effectiveness of CPR is to measure aortic diastolic blood pressure or coronary perfusion pressure (25). When heart muscles do not receive adequate blood flow and/or oxygen, their energy substrate is depleted. In turn, heart muscles stop contracting and the heart stops pumping. To restart the cardiac pump, it is critical that myocardial perfusion with oxygenated blood is reestablished. In acidotic asphyxiated neonates, there is loss of peripheral vascular tone, i.e., maximum vasodilation. When chest compressions are performed, blood from the cardiac chambers takes the path of least resistance and thus preferentially flows through aorta and into peripheral circulation rather than into narrow more constricted coronary arteries that have high resistance (Figure 1). The use of epinephrine in this situation results in intense peripheral vasoconstriction. This elevates the aortic to right atrial pressure gradient during the relaxation phase

\section{Coronary Perfusion Pressure $=$ Aortic DBP - Right Atrial DBP}
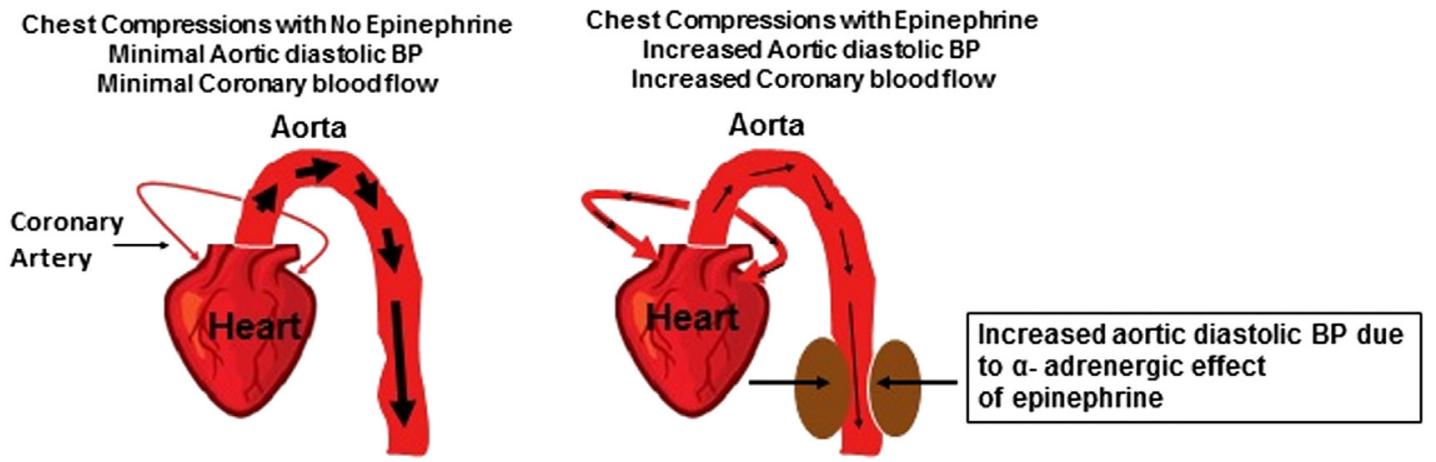

FIGURE 1 | Epinephrine and coronary perfusion pressure. 
of CPR (26-29). Due to this pressure gradient, blood during chest compressions enters the coronary arteries and myocardial blood flow increases. Hence, this pressure gradient is called the coronary perfusion pressure. As oxygenated blood enters the coronary circulation, it facilitates resynthesis of adenosine triphosphate within myocardial mitochondria improving myocardial contractility and viability. In animal models and humans, coronary perfusion pressure correlates directly with myocardial blood flow, which is a good predictor of ROSC.

Although minor, $\beta 2$ receptor-mediated coronary vasodilation may contribute to improved coronary perfusion following epinephrine administration $(10,21,30)$. Cerebral electrographic activity and cerebral oxygen uptake improves following epinephrine administration during $\mathrm{CPR}$ as cerebral blood flow increases due to epinephrine-induced peripheral vasoconstriction $(28,29)$. Through its $\alpha$ receptor stimulation, epinephrine may counteract carotid artery collapse induced by elevated intrathoracic pressures due to CPR and further optimize blood flow (28).

Studies utilizing posttransition asphyxia animal model have demonstrated the importance of epinephrine, where after asphyxia cardiac arrest, chest compressions alone were ineffective, but majority of animals reached the critical diastolic blood pressure (rising aortic to right atrial pressure gradient) and ROSC after epinephrine administration (31-33). It is important to note that these studies also showed that interruptions in chest compression lead to lowering of diastolic blood pressure, thus highlighting the importance of minimizing interruptions in cardiac compressions during CPR (31-33).

The majority of the above information was obtained from adult animal studies, posttransitioned neonatal animal studies, or human adult studies. No studies in term or preterm newborns or animal models with newborn transition physiology have investigated the mechanism of action of epinephrine during CPR. The distribution and maturation of $\alpha$ and $\beta$ receptors in term and preterm newborns remain unknown (23).

\section{CURRENT INDICATION FOR EPINEPHRINE DURING NEONATAL CPR}

Bradycardia in newly born infants is usually the result of inadequate aeration of lungs and ventilation or profound hypoxemia and acidosis from prior poor placental perfusion. Hence, effective ventilation is the top priority during delivery room resuscitation of the bradycardic newborn. Current resuscitation guidelines recommend that epinephrine should be used if the newborn remains bradycardic with heart rate $<60 \mathrm{bpm}$ after $30 \mathrm{~s}$ of what appears to be effective ventilation with chest rise, followed by $30 \mathrm{~s}$ of coordinated chest compressions and ventilations $(1,8,9)$.

\section{OPTIMAL DOSE AND ROUTE OF ADMINISTRATION OF EPINEPHRINE DURING CPR}

Epinephrine during neonatal CPR in the delivery room can be given by three routes: intravenous, endotracheal (ET), and intraosseous (Table 1).
TABLE 1 | Epinephrine use during newborn resuscitation: route, dose, and summary of evidence.

\begin{tabular}{|c|c|c|}
\hline Route & Dose & Summary of evidence \\
\hline Intravenous & $0.01-0.03 \mathrm{mg} / \mathrm{kg}$ & $\begin{array}{l}\text { - Preferred route and appear to be more } \\
\text { efficacious than other routes } \\
\text { - Dose extrapolated from adult experience } \\
\text { - High-dose epinephrine offers no } \\
\text { advantage and is associated with } \\
\text { increased postresuscitation adverse } \\
\text { effects and increased mortality } \\
\text { - Dose escalation studies in neonatal } \\
\text { animal model with transition physiology } \\
\text { are urgently needed }\end{array}$ \\
\hline $\begin{array}{l}\text { Endotracheal } \\
\text { (ET) }\end{array}$ & $0.05-0.1 \mathrm{mg} / \mathrm{kg}$ & $\begin{array}{l}\text { - Less effective than IV route } \\
\text { - Achieved plasma concentration is less } \\
\text { and it peaks slower with ET epinephrine } \\
\text { compared to IV epinephrine } \\
\text { - Can be used until IV access is available }\end{array}$ \\
\hline Intraosseous & $0.01-0.03 \mathrm{mg} / \mathrm{kg}$ & $\begin{array}{l}\text { - Limited evidence compared to IV route } \\
\text { - Providers frequently involved in newborn } \\
\text { resuscitation feel more comfortable with } \\
\text { rapid UVC insertion compared to IO route }\end{array}$ \\
\hline Intramuscular & Not recommended & $\begin{array}{l}\text { - Very limited evidence } \\
\text { - Significant tissue damage at local site }\end{array}$ \\
\hline
\end{tabular}

\section{Intravenous Epinephrine}

This is the preferred route of administration during neonatal $\mathrm{CPR}$ in the delivery room as it appears to be more efficacious compared to other routes $(1,8,9)$. The umbilical vein is a rapidly accessible, direct intravenous route. If epinephrine use is anticipated based on risk factors and no response to optimized positive-pressure ventilation (preferably via a secured airway), one team member should prepare to place an umbilical venous catheter, while the others continue to provide ventilation and chest compression. Chest compressions should be provided from head of the bed to allow adequate access to place the umbilical venous catheter (1).

The optimal dose of intravenous epinephrine has been the subject of much debate. In animal ventricular fibrillation models, Redding and Pearson demonstrated that intravenous epinephrine of $1 \mathrm{mg}(0.1 \mathrm{mg} / \mathrm{kg}$ in $10 \mathrm{~kg}$ dogs) increased ROSC when combined with ventilation and chest compressions alone (19). Human studies following this study did not take into account the weight difference between the $10-\mathrm{kg}$ dogs that were studied and the average adult weight, which is 7 - to 10 -fold more. Surprisingly, even with such low doses, epinephrine was reported to be effective in achieving ROSC in adult CPR (34). As there are no neonatal epinephrine dosing studies, the recommended dose was extrapolated from the adult experience with a suggested dosing range of $0.01-0.03 \mathrm{mg} / \mathrm{kg}$. Given the overlooked weight difference between dogs in the study by Redding and Pearson (19) and humans, studies were conducted to see if higher dose epinephrine would be more efficacious. Initially, studies in ventricular fibrillation adult animal model showed increased ROSC and improved cerebral and coronary blood flow with escalating doses of epinephrine (35). Based on these data, adult and pediatric resuscitation guidelines started recommending using $0.1 \mathrm{mg} / \mathrm{kg}$ high dose of epinephrine if no response was seen with standard dose epinephrine (36). 
Clinical studies conducted later found that high-dose epinephrine $(0.1 \mathrm{mg} / \mathrm{kg})$ is not more effective and may be harmful $(35,37,38)$.

\section{Animal Data}

Berg et al. in a pediatric asphyxia swine model demonstrated that high-dose epinephrine did not result in increased ROSC, and in fact, there was higher postresuscitation mortality (39). Burchfield et al. in a neonatal lamb model demonstrated that high-dose epinephrine reduced stroke volume and cardiac output (40). McCaul et al. demonstrated dose-related adverse outcomes with higher tachycardia, hypertension, mortality, and increased troponin with high-dose epinephrine in a rat model (41). Observation of hypertension following hypotension with high-dose epinephrine is especially important for preterm newborns who are vulnerable to development of intraventricular hemorrhage with fluctuations in blood pressure $(42,43)$.

\section{Adult Data}

Meta-analysis of randomized control trials in adult cardiac arrest patients demonstrated increased ROSC with high-dose epinephrine but no improvement in survival to hospital discharge (35).

\section{Older Children}

Perondi et al. randomized 68 children (mean age of 6 years) to either 0.1 versus $0.01 \mathrm{mg} / \mathrm{kg}$ for the second dose of epinephrine after failure of standard first dose $(0.01 \mathrm{mg} / \mathrm{kg})(38)$. This study demonstrated that ROSC rates were similar between both groups. Alarmingly, no child survived in the high-dose epinephrine group compared to $21 \%$ survival in the standard epinephrine group. Patterson et al. confirmed these findings that high-dose epinephrine did not confer any benefits but reduced survival when arrest was precipitated by asphyxia (37).

\section{Neonatal Data}

There is a stark absence of any neonatal studies including randomized controlled trials studying any dose of epinephrine. Halling et al. described in an observational study of $20 \%$ success rate with single standard dose of IV epinephrine. Multiple doses were needed by large number of newborns (3).

In summary, these data suggest that there is no advantage with high-dose epinephrine, and it is associated with postresuscitation hypertension, tachycardia, and increased mortality especially following cardiac arrest from asphyxia. Neonatal data remain sparse, and dose escalation studies in appropriate neonatal models with transition physiology are urgently needed.

\section{ET Epinephrine}

Although the ET route is readily available and less time consuming than establishing an intravenous or intraosseous access, it appears to be less effective $(36,44,45)$. However, until intravenous access is available, some clinicians may choose to give epinephrine ET $(1,9)$. Currently, the recommended dose is $0.05-0.1 \mathrm{mg}$ / $\mathrm{kg}$, which is much higher than the recommended intravenous epinephrine dose $(1,9)$.

\section{Adult Animal Data}

Redding et al. were the first to suggest the use of ET epinephrine during cardiac arrest (46). In a ventricular fibrillation pig model, Crespo et al. compared 0.01 versus $0.1 \mathrm{mg} / \mathrm{kg}$ ET epinephrine doses (47). The study demonstrated that higher dose was able to achieve higher plasma concentrations of the drug but that did not translate to higher blood pressure. Roberts et al. also investigated different ET epinephrine doses and compared them with equivalent intravenous epinephrine doses (48). The study demonstrated that the peak concentration of epinephrine was found in $15 \mathrm{~s}$ after either route of administration, but with ET epinephrine, blood concentrations were more sustained. Importantly maximum plasma concentration achieved by ET epinephrine was one-tenth of the plasma concentration achieved by the intravenous route. Vali and Lakshminrusimha conducted a study of ET versus intravenous epinephrine in a fetal lamb model of asphyxia where animals had not yet transitioned to newborn circulation (49). They demonstrated that plasma epinephrine peaks much faster and higher compared to ET epinephrine although no difference in rates of ROSC was observed between either group.

\section{Human Adult Data}

Many retrospective adult case series have noted ET epinephrine to be less effective than IV epinephrine in achieving ROSC during CPR $(36,44,45)$.

\section{Neonatal Data}

Four case series in neonates noted some evidence of absorption or cardiovascular improvement following ET epinephrine administration, but doses were 10 times higher than typical intravenous doses, and the majority of newborns had bradycardia, not asystole (50-52). Barber and Wyckoff reported on a retrospective review of all neonates who received epinephrine in the delivery room during the study period (2). The study demonstrated that the majority of infants received their first dose as ET epinephrine. They found that ET epinephrine dose of 0.01-0.03 $\mathrm{mg} / \mathrm{kg}$ failed to re-establish HR > $60 \mathrm{bpm}$ two-thirds of time. In the neonates who failed to respond to ET epinephrine, $77 \%$ of them responded to subsequent intravenous epinephrine. ET epinephrine efficacy may be limited in the newly born due to dilution by non-mobilized lung fluid. Elevated pulmonary arterial pressure in the presence of patent ductus arteriosus could result in right-sided cardiac output bypassing the lungs and thus limiting epinephrine absorption from the lung $(23,25)$. Based on this evidence, guidelines recommended an increase in ET epinephrine dosing from 0.01 to 0.03 to 0.05 to $0.1 \mathrm{mg} / \mathrm{kg}$ $(1,9)$. Halling et al. presented a retrospective review comparing the dosing from 0.03 to $0.05 \mathrm{mg} / \mathrm{kg}$ (3). They found no improvement in rates or time of ROSC with the higher ET epinephrine dose. It is possible that there may not be an optimal ET epinephrine dose. Current guidelines stress the importance of education, practice, and preparation to rapidly establish IV access in delivery room for newborns who need epinephrine during delivery room resuscitation (9).

\section{Intraosseous Epinephrine}

Simulation studies have shown that for inexperienced personnel, establishment of an intraosseous line was faster and easier than the placement of umbilical catheters (53). In a neonatal case series of 27 neonates who received intraosseous epinephrine for resuscitation, no short-term complications were demonstrated 
(54). Also many critical clinical outcomes were not described. Given the comfort level that can be achieved by neonatal providers for rapid placement of umbilical catheters and limited evidence regarding IO placement in delivery room, IV epinephrine is preferred (1).

\section{Intramuscular Epinephrine}

Mauch et al. demonstrated that $0.1 \mathrm{mg} / \mathrm{kg}$ of IM epinephrine resulted in similar ROSC and survival in infant piglet cardiac arrest model (55). Case reports indicate that intramuscular epinephrine of $0.02 \mathrm{mg} / \mathrm{kg}$ causes significant tissue damage at injection site (56). Currently, intramuscular epinephrine is not recommended for neonatal CPR.

\section{ADVERSE EFFECTS OF USE OF EPINEPHRINE DURING CPR}

Epinephrine especially with repeated doses or with high doses can cause postresuscitation hypertension and tachycardia $(39,57)$. This can result in injury to various organ systems especially in preterm neonates. Excess epinephrine due to its vasoconstrictive properties can impair blood flow to various organs such as kidneys and intestines. Epinephrine can also result in elevation of pulmonary arterial pressures and increase myocardial oxygen consumption and demand through its $\beta$ adrenergic effects $(58,59)$. This may be detrimental especially in situations where hypoxia persists and oxygen delivery is impaired. It has also been associated with imbalance of various neurotransmitters such as gamma-aminobutyric acid, dopamine, serotonin, acetylcholine (60-63). It can impair blood-brain barrier and possibly decrease the threshold for seizures $(62,64)$.

\section{ALTERNATIVES TO EPINEPHRINE IN DR}

Given the limitations of epinephrine in neonatal CPR, there is a great interest in finding other vasoconstrictors that have fewer detrimental side effects. Vasopressin has been studied in the adult literature as an alternative. Endogenous vasopressin levels were found to be higher in successfully resuscitated adults compared to those who died. Vasopressin through V1 receptors is a potent vasoconstrictor of blood vessels in the skin, skeletal muscle, and mesenteric blood vessels $(10,65,66)$. It does not have any stimulant effect on the myocardium, and at low doses, it can vasodilate coronary, pulmonary, and cerebral vessels. Even though it has these theoretical benefits over epinephrine, in randomized control trials in adults, vasopressin has not found to be more effective than epinephrine (67). A cohort study on pediatric in-hospital cardiac arrest vasopressin was found to be less effective and associated with higher mortality (68). In neonatal piglet posttransition asphyxia model, McNamara et al. showed that vasopressin resulted in improved survival, lower postresuscitation troponin, and less hemodynamic compromise compared to epinephrine (69). No human neonatal data exist regarding vasopressin in CPR. Studies with neonatal animal models with transition physiology are urgently needed.

\section{OTHER CONSIDERATIONS FOR EPINEPHRINE IN THE DELIVERY ROOM}

\section{Interval between Doses}

The current recommendation is to repeat the dose of IV epinephrine every 3-5 min if the heart rate remains less than $60 \mathrm{bpm}$ $(1,9)$. Vali and Lakshminrusimha in a fetal lamb asphyxia model demonstrated an incremental increase in plasma epinephrine concentration with repeated IV epinephrine doses every 3-5 min (49). Warren et al. performed retrospective review of in-hospital cardiac arrest in adults and found the optimal interval to repeat dose to be 9-10 min instead of 3-5 min (70). Linner et al. gave epinephrine before chest compressions to bradycardic and severely asphyxiated newborn piglets and demonstrated that this strategy did not improve ROSC or cerebral circulation (71). More studies are needed to find out optimal interval between doses, but current evidence would suggest that more frequent or early epinephrine does not seem to be more beneficial.

\section{Flush Volume after IV Epinephrine Dose through Low UVC}

Currently recommended flush volume after IV epinephrine dose is $0.5-1 \mathrm{ml}(1)$. Vali and Lakshminrusimha showed higher incidence of ROSC and faster ROSC with right atrial epinephrine compared to low UVC epinephrine in fetal lamb asphyxia model (49). It is possible that the currently recommended flush volume will deposit the epinephrine in umbilical vein but might not be enough to reach the heart. It is unclear if current flush volume is adequate and if higher flush volume may result in faster rise and higher epinephrine plasma concentrations. Studies are underway to answer this question.

\section{OUTCOMES IN NEWBORNS WHO REQUIRE EPINEPHRINE IN THE DELIVERY ROOM}

Cohort study data suggest that epinephrine is needed in $<0.1 \%$ of all liver born deliveries $(2,3)$ although there is a large variation among different centers. Severe fetal acidemia, malpositioned ET tubes, and ineffective ventilator support contribute to the higher use of delivery room epinephrine $(72,73)$. Thus, it remains critical that neonatal providers focus on optimizing positive-pressure ventilation including placement of an alternate airway as a part of their ventilation corrective measures if a newborn is not responding to initial positive-pressure ventilation. Provision of effective ventilation that moves the chest should eliminate or reduce unnecessary intensive CPR. Term infants who require intensive CPR including multiple epinephrine doses and those whose Apgar score remain low at $10 \mathrm{~min}$ of life suffer from high incidence of death or poor neurodevelopmental outcomes $(4,5)$. In preterm infants due to lack of good evidence for use of epinephrine and its adverse effects of epinephrine especially postresuscitation hypertension, outcome data become even more important. Multiple retrospective observational studies have noted that preterm neonates requiring $\mathrm{CPR}$ and epinephrine have significantly lower 
survival, higher incidence of early onset sepsis, NEC, grade 3-4 intraventricular hemorrhage, cystic periventricular leukomalacia, bronchopulmonary dysplasia, and neurodevelopmental impairment $(7,74-76)$. These studies frequently suffer from small numbers and selection bias as the most compromised and sicker preterm neonates may require CPR but all studies point toward worse outcomes associated with extensive delivery room CPR. These data suggest that optimization of CPR and epinephrine use in delivery room has potential to impact outcomes significantly.

\section{CONCLUSION}

Epinephrine use in delivery room remains uncommon especially when neonatal providers focus on effective positive-pressure ventilation. Epinephrine use in delivery room is associated with high mortality and poor long-term outcomes. Recommendations regarding epinephrine use including dose and route are based mostly on extrapolation of data from animals or adult literature. Even the majority of available animal data come from ventricular fibrillation cardiac arrest models and posttransition models that

\section{REFERENCES}

1. Weiner GM, Zaichkin J. Textbook of Neonatal Resuscitation (NRP). 7th ed. Elk Grove Village, IL: American Academy of Pediatrics (2016).

2. Barber CA, Wyckoff MH. Use and efficacy of endotracheal versus intravenous epinephrine during neonatal cardiopulmonary resuscitation in the delivery room. Pediatrics (2006) 118(3):1028-34. doi:10.1542/peds.2006-0416

3. Halling C, Sparks JE, Christie L, Wyckoff MH. Efficacy of intravenous and endotracheal epinephrine during neonatal cardiopulmonary resuscitation in the delivery room. J Pediatr (2017). doi:10.1016/j.jpeds.2017.02.024

4. Chawla S, Foglia EE, Kapadia V, Wyckoff MH. Perinatal management: what has been learned through the network? Semin Perinatol (2016) 40(6):391-7. doi:10.1053/j.semperi.2016.05.006

5. Laptook AR, Shankaran S, Ambalavanan N, Carlo WA, McDonald SA, Higgins RD, et al. Hypothermia Subcommittee of the NNRN. Outcome of term infants using Apgar scores at 10 minutes following hypoxic-ischemic encephalopathy. Pediatrics (2009) 124(6):1619-26. doi:10.1542/peds.2009-0934

6. Wyckoff MH, Salhab WA, Heyne RJ, Kendrick DE, Stoll BJ, Laptook AR, et al. Outcome of extremely low birth weight infants who received delivery room cardiopulmonary resuscitation. J Pediatr (2012) 160(2):239-44.e2. doi:10.1016/j.jpeds.2011.07.041

7. Harrington DJ, Redman CW, Moulden M, Greenwood CE. The long-term outcome in surviving infants with Apgar zero at 10 minutes: a systematic review of the literature and hospital-based cohort. Am J Obstet Gynecol (2007) 196(5): 463.e1-5. doi:10.1016/j.ajog.2006.10.877

8. Perlman JM, Wyllie J, Kattwinkel J, Wyckoff MH, Aziz K, Guinsburg R, et al. Part 7: neonatal resuscitation: 2015 international consensus on cardiopulmonary resuscitation and emergency cardiovascular care science with treatment recommendations. Circulation (2015) 132(16 Suppl 1):S204-41. doi:10.1161/ CIR.0000000000000276

9. Wyckoff MH, Aziz K, Escobedo MB, Kapadia VS, Kattwinkel J, Perlman JM, et al. Part 13: neonatal resuscitation: 2015 American Heart Association guidelines update for cardiopulmonary resuscitation and emergency cardiovascular care (reprint). Pediatrics (2015) 136(Suppl 2):S196-218. doi:10.1542/ peds.2015-3373G

10. Weiner GM, Niermeyer S. Medications in neonatal resuscitation: epinephrine and the search for better alternative strategies. Clin Perinatol (2012) 39(4):843-55. doi:10.1016/j.clp.2012.09.005

11. Wyckoff MH, Perlman J, Niermeyer S. Medications during resuscitation - what is the evidence? Semin Neonatol (2001) 6(3):251-9. doi:10.1053/siny.2001.0053

12. Raju TN. History of neonatal resuscitation. Tales of heroism and desperation. Clin Perinatol (1999) 26(3):629-40, vi-vii. have little in common with newborns in the delivery room. There is a scarcity of human neonatal term and preterm epinephrine data even in the form of observational studies. Based on the limited available literature, intravenous epinephrine is preferred to ET epinephrine. Clinical and animal studies in transition neonatal models are urgently needed to identify optimal indication, timing, dose, route, and alternatives to epinephrine in neonatal CPR.

\section{AUTHOR CONTRIBUTIONS}

VK performed the literature review, created first draft of the article, revised the draft, and created and approved the final draft of the article. MW critically reviewed the first draft, revised the draft, approved the final draft of the article, and contributed substantially to this manuscript.

\section{FUNDING}

This work was supported by NICHD/NIH 1K23HD083511-01A1 (to VK).

13. Wyllie J, Niermeyer S. The role of resuscitation drugs and placental transfusion in the delivery room management of newborn infants. Semin Fetal Neonatal Med (2008) 13(6):416-23. doi:10.1016/j.siny.2008.04.017

14. Iacovidou N, Vasileiou PV, Papalois A, Syggelou A, Bassareo PP, Xanthos T. Drugs in newborn resuscitation: the more we learn the least we use. Curr Med Chem (2012) 19(27):4606-16. doi:10.2174/092986712803306303

15. Oliver GS, Schafer EA. On the physiological action of extract of the suprarenal capsules. J Physiol Lond (1894) 16:i-iv. 77.

16. Aronson JK. "Where name and image meet" - the argument for "adrenaline". $B M J(2000)$ 320(7233):506-9. doi:10.1136/bmj.320.7233.506

17. Crile G, Dolley DH. An experimental research into the resuscitation of dogs killed by anesthetics and asphyxia. J Exp Med (1906) 8(6):713-25. doi:10.1084/ jem.8.6.713

18. Wiggers CJ. Cardiac massage followed by countershock in revival of mammalian ventricles from fibrillation due to coronary occlusion. Am J Physiol (1936) 116:161.

19. Redding JS, Pearson JW. Evaluation of drugs for cardiac resuscitation. Anesthesiology (1963) 24:203-7. doi:10.1097/00000542-196303000-00008

20. Devic E, Xiang Y, Gould D, Kobilka B. Beta-adrenergic receptor subtypespecific signaling in cardiac myocytes from beta(1) and beta(2) adrenoceptor knockout mice. Mol Pharmacol (2001) 60(3):577-83.

21. Kuznetsov V, Pak E, Robinson RB, Steinberg SF. Beta 2-adrenergic receptor actions in neonatal and adult rat ventricular myocytes. Circ Res (1995) 76(1): 40-52. doi:10.1161/01.RES.76.1.40

22. Polin RA, Abman SH. Fetal and Neonatal Physiology. 4th ed. Philadelphia: Elsevier/Saunders (2011).

23. Pinto M, Solevag AL, O’Reilly M, Aziz K, Cheung PY, Schmolzer GM. Evidence on adrenaline use in resuscitation and its relevance to newborn infants: a non-systematic review. Neonatology (2016) 111(1):37-44. doi:10.1159/ 000447960

24. Otto CW, Yakaitis RW, Blitt CD. Mechanism of action of epinephrine in resuscitation from asphyxial arrest. Crit Care Med (1981) 9(4):321-4. doi:10.1097/ 00003246-198104000-00008

25. Wyckoff MH. Neonatal cardiopulmonary resuscitation: critical hemodynamics. Neoreviews (2010) 11(3):e123-9. doi:10.1542/neo.11-3-e123

26. Brown CG, Werman HA, Davis EA, Katz S, Hamlin RL. The effect of high-dose phenylephrine versus epinephrine on regional cerebral blood flow during CPR. Ann Emerg Med (1987) 16(7):743-8. doi:10.1016/S0196-0644(87)80566-8

27. Burnett AM, Segal N, Salzman JG, McKnite MS, Frascone RJ. Potential negative effects of epinephrine on carotid blood flow and ETCO2 during active compression-decompression CPR utilizing an impedance threshold device. Resuscitation (2012) 83(8):1021-4. doi:10.1016/j.resuscitation.2012.03.018 
28. Michael JR, Guerci AD, Koehler RC, Shi AY, Tsitlik J, Chandra N, et al. Mechanisms by which epinephrine augments cerebral and myocardial perfusion during cardiopulmonary resuscitation in dogs. Circulation (1984) 69(4):822-35. doi:10.1161/01.CIR.69.4.822

29. Schleien CL, Dean JM, Koehler RC, Michael JR, Chantarojanasiri T, Traystman R, et al. Effect of epinephrine on cerebral and myocardial perfusion in an infant animal preparation of cardiopulmonary resuscitation. Circulation (1986) 73(4):809-17. doi:10.1161/01.CIR.73.4.809

30. Gao F, de Beer VJ, Hoekstra M, Xiao C, Duncker DJ, Merkus D. Both beta1and beta2-adrenoceptors contribute to feedforward coronary resistance vessel dilation during exercise. Am J Physiol Heart Circ Physiol (2010) 298(3):H921-9. doi:10.1152/ajpheart.00135.2009

31. Sobotka KS, Polglase GR, Schmolzer GM, Davis PG, Klingenberg C, Hooper SB. Effects of chest compressions on cardiovascular and cerebral hemodynamics in asphyxiated near-term lambs. Pediatr Res (2015) 78(4):395-400. doi:10.1038/pr.2015.117

32. Solevag AL, Dannevig I, Wyckoff M, Saugstad OD, Nakstad B. Extended series of cardiac compressions during CPR in a swine model of perinatal asphyxia. Resuscitation (2010) 81(11):1571-6. doi:10.1016/j.resuscitation.2010. 06.007

33. Solevag AL, Dannevig I, Wyckoff M, Saugstad OD, Nakstad B. Return of spontaneous circulation with a compression:ventilation ratio of 15:2 versus 3:1 in newborn pigs with cardiac arrest due to asphyxia. Arch Dis Child Fetal Neonatal Ed (2011) 96(6):F417-21. doi:10.1136/adc.2010.200386

34. Pearson JW, Redding JS. The role of epinephrine in cardiac resuscitation. Anesth Analg (1963) 42:599-606. doi:10.1213/00000539-196309000-00022

35. Vandycke C, Martens P. High dose versus standard dose epinephrine in cardiac arrest - a meta-analysis. Resuscitation (2000) 45(3):161-6. doi:10.1016/ S0300-9572(00)00188-X

36. Wyckoff MH, Perlman JM. Use of high-dose epinephrine and sodium bicarbonate during neonatal resuscitation: is there proven benefit? Clin Perinatol (2006) 33(1):141-51, viii-ix. doi:10.1016/j.clp.2005.11.016

37. Patterson MD, Boenning DA, Klein BL, Fuchs S, Smith KM, Hegenbarth MA, et al. The use of high-dose epinephrine for patients with out-of-hospital cardiopulmonary arrest refractory to prehospital interventions. Pediatr Emerg Care (2005) 21(4):227-37. doi:10.1097/01.pec.0000161468.12218.02

38. Perondi MB, Reis AG, Paiva EF, Nadkarni VM, Berg RA. A comparison of high-dose and standard-dose epinephrine in children with cardiac arrest. N Engl J Med (2004) 350(17):1722-30. doi:10.1056/NEJMoa032440

39. Berg RA, Otto CW, Kern KB, Hilwig RW, Sanders AB, Henry CP, et al. A randomized, blinded trial of high-dose epinephrine versus standard-dose epinephrine in a swine model of pediatric asphyxial cardiac arrest. Crit Care Med (1996) 24(10):1695-700. doi:10.1097/00003246-199610000-00016

40. Burchfield DJ, Preziosi MP, Lucas VW, Fan J. Effects of graded doses of epinephrine during asphxia-induced bradycardia in newborn lambs. Resuscitation (1993) 25(3):235-44. doi:10.1016/0300-9572(93)90120-F

41. McCaul CL, McNamara PJ, Engelberts D, Wilson GJ, Romaschin A, Redington AN, et al. Epinephrine increases mortality after brief asphyxial cardiac arrest in an in vivo rat model. Anesth Analg (2006) 102(2):542-8. doi:10.1213/01.ane.0000195231.81076.88

42. Noori S, Seri I. Hemodynamic antecedents of peri/intraventricular hemorrhage in very preterm neonates. Semin Fetal Neonatal Med (2015) 20(4):232-7. doi:10.1016/j.siny.2015.02.004

43. Volpe JJ, editor. Intracranial hemorrhage: germinal matrix-intraventricular hemorrhage. Neurology of the Newborn. Philadelphia: Saunders (2008). 517 p.

44. Niemann JT, Stratton SJ, Cruz B, Lewis RJ. Endotracheal drug administration during out-of-hospital resuscitation: where are the survivors? Resuscitation (2002) 53(2):153-7. doi:10.1016/S0300-9572(02)00004-7

45. Quinton DN, O'Byrne G, Aitkenhead AR. Comparison of endotracheal and peripheral intravenous adrenaline in cardiac arrest. Is the endotracheal route reliable? Lancet (1987) 1(8537):828-9.

46. Redding JS, Asuncion JS, Pearson JW. Effective routes of drug administration during cardiac arrest. Anesth Analg (1967) 46(2):253-8. doi:10.1213/ 00000539-196703000-00033

47. Crespo SG, Schoffstall JM, Fuhs LR, Spivey WH. Comparison of two doses of endotracheal epinephrine in a cardiac arrest model. Ann Emerg Med (1991) 20(3):230-4. doi:10.1016/S0196-0644(05)80928-X
48. Roberts JR, Greenberg MI, Knaub MA, Kendrick ZV, Baskin SI. Blood levels following intravenous and endotracheal epinephrine administration. JACEP (1979) 8(2):53-6. doi:10.1016/S0361-1124(79)80036-2

49. Vali P, Lakshminrusimha S. Epinephrine in Neonatal Resuscitation in a Term Lamb Model of Perinatal Asphyxial Arrest. Baltimore, MD: Pediatric Academic Society (2015)

50. Jankov RP, Asztalos EV, Skidmore MB. Favourable neurological outcomes following delivery room cardiopulmonary resuscitation of infants $<$ or $=$ $750 \mathrm{~g}$ at birth. J Paediatr Child Health (2000) 36(1):19-22. doi:10.1046/j. 1440-1754.2000.00434.x

51. Lindemann R. Resuscitation of the newborn. Endotracheal administration of epinephrine. Acta Paediatr Scand (1984) 73(2):210-2. doi:10.1111/j. 1651-2227.1984.tb09930.x

52. Schwab KO, von Stockhausen HB. Plasma catecholamines after endotracheal administration of adrenaline during postnatal resuscitation. Arch Dis Child Fetal Neonatal Ed (1994) 70(3):F213-7. doi:10.1136/fn.70.3.F213

53. Abe KK, Blum GT, Yamamoto LG. Intraosseous is faster and easier than umbilical venous catheterization in newborn emergency vascular access models. Am J Emerg Med (2000) 18(2):126-9. doi:10.1016/S0735-6757(00)90001-9

54. Ellemunter H, Simma B, Trawoger R, Maurer H. Intraosseous lines in preterm and full term neonates. Arch Dis Child Fetal Neonatal Ed (1999) 80(1):F74-5. doi:10.1136/fn.80.1.F74

55. Mauch J, Ringer SK, Spielmann N, Weiss M. Intravenous versus intramuscular epinephrine administration during cardiopulmonary resuscitation - a pilot study in piglets. Paediatr Anaesth (2013) 23(10):906-12. doi:10.1111/pan.12149

56. Doglioni N, Chiandetti L, Trevisanuto D. Intramuscolar epinephrine during neonatal resuscitation. Resuscitation (2015) 90:e5. doi:10.1016/j.resuscitation. 2014.08.039

57. Hilwig RW, Kern KB, Berg RA, Sanders AB, Otto CW, Ewy GA. Catecholamines in cardiac arrest: role of alpha agonists, beta-adrenergic blockers and highdose epinephrine. Resuscitation (2000) 47(2):203-8. doi:10.1016/S0300-9572 (00)00261-6

58. Hornchen U, Schuttler J, Stoeckel H, Eichelkraut W, Hahn N. Endobronchial instillation of epinephrine during cardiopulmonary resuscitation. Crit Care Med (1987) 15(11):1037-9. doi:10.1097/00003246-198711000-00009

59. Tang W, Weil MH, Sun S, Noc M, Yang L, Gazmuri RJ. Epinephrine increases the severity of postresuscitation myocardial dysfunction. Circulation (1995) 92(10):3089-93. doi:10.1161/01.CIR.92.10.3089

60. Anju TR, Abraham PM, Antony S, Paulose CS. Alterations in cortical GABAB receptors in neonatal rats exposed to hypoxic stress: role of glucose, oxygen, and epinephrine resuscitation. Mol Cell Biochem (2010) 343(1-2):1-11. doi:10.1007/s11010-010-0491-9

61. Anju TR, Korah PK, Jayanarayanan S, Paulose CS. Enhanced brain stem 5HT(2) A receptor function under neonatal hypoxic insult: role of glucose, oxygen, and epinephrine resuscitation. Mol Cell Biochem (2011) 354(1-2):151-60. doi:10.1007/s11010-011-0814-5

62. Chathu F, Krishnakumar A, Paulose CS. Acetylcholine esterase activity and behavioral response in hypoxia induced neonatal rats: effect of glucose, oxygen and epinephrine supplementation. Brain Cogn (2008) 68(1):59-66. doi:10.1016/j.bandc.2008.02.124

63. Joseph B, Nandhu MS, Paulose CS. Dopamine D1 and D2 receptor functional down regulation in the cerebellum of hypoxic neonatal rats: neuroprotective role of glucose and oxygen, epinephrine resuscitation. Pharmacol Res (2010) 61(2):136-41. doi:10.1016/j.phrs.2009.08.007

64. Johansson BB, Martinsson L. Blood-brain barrier to albumin in awake rats in acute hypertension induced by adrenaline, noradrenaline or angiotensin. Acta Neurol Scand (1979) 60(4):193-7. doi:10.1111/j.1600-0404.1979.tb02969.x

65. Ornato JP. Optimal vasopressor drug therapy during resuscitation. Crit Care (2008) 12(2):123. doi:10.1186/cc6824

66. Treschan TA, Peters J. The vasopressin system: physiology and clinical strategies. Anesthesiology (2006) 105(3):599-612; quiz 639-40. doi:10.1097/ 00000542-200609000-00026

67. Morrison LJ, Deakin CD, Morley PT, Callaway CW, Kerber RE, Kronick SL, et al. Part 8: advanced life support: 2010 international consensus on cardiopulmonary resuscitation and emergency cardiovascular care science with treatment recommendations. Circulation (2010) 122(16 Suppl 2):S345-421. doi:10.1161/ CIRCULATIONAHA.110.971051 
68. Duncan JM, Meaney P, Simpson P, Berg RA, Nadkarni V, Schexnayder $\mathrm{S}$, et al. Vasopressin for in-hospital pediatric cardiac arrest: results from the American Heart Association National Registry of Cardiopulmonary Resuscitation. Pediatr Crit Care Med (2009) 10(2):191-5. doi:10.1097/ PCC.0b013e31819a36f2

69. McNamara PJ, Engelberts D, Finelli M, Adeli K, Kavanagh BP. Vasopressin improves survival compared with epinephrine in a neonatal piglet model of asphyxial cardiac arrest. Pediatr Res (2014) 75(6):738-48. doi:10.1038/ pr.2014.38

70. Warren SA, Huszti E, Bradley SM, Chan PS, Bryson CL, Fitzpatrick AL, et al. Adrenaline (epinephrine) dosing period and survival after in-hospital cardiac arrest: a retrospective review of prospectively collected data. Resuscitation (2014) 85(3):350-8. doi:10.1016/j.resuscitation.2013.10.004

71. Linner R, Werner O, Perez-de-Sa V, Cunha-Goncalves D. Early adrenaline administration does not improve circulatory recovery during resuscitation from severe asphyxia in newborn piglets. Resuscitation (2012) 83(10): 1298-303. doi:10.1016/j.resuscitation.2012.02.030

72. Kapadia VS, Wyckoff MH. Drugs during delivery room resuscitation - what, when and why? Semin Fetal Neonatal Med (2013) 18(6):357-61. doi:10.1016/j. siny.2013.08.001

73. Perlman JM, Risser R. Cardiopulmonary resuscitation in the delivery room. Associated clinical events. Arch Pediatr Adolesc Med (1995) 149(1):20-5. doi:10.1001/archpedi.1995.02170130022005
74. Frontanes A, Garcia-Fragoso L, Garcia I, Rivera J, Valcarcel M. Outcome of very-low-birth-weight infants who received epinephrine in the delivery room. Resuscitation (2011) 82(4):427-30. doi:10.1016/j. resuscitation.2010.11.020

75. Handley SC, Sun Y, Wyckoff MH, Lee HC. Outcomes of extremely preterm infants after delivery room cardiopulmonary resuscitation in a population-based cohort. J Perinatol (2015) 35(5):379-83. doi:10.1038/ jp. 2014.222

76. Shah PS, Shah P, Tai KF. Chest compression and/or epinephrine at birth for preterm infants $<32$ weeks gestational age: matched cohort study of neonatal outcomes. J Perinatol (2009) 29(10):693-7. doi:10.1038/jp.2009.70

Conflict of Interest Statement: The authors declare that the research was conducted in the absence of any commercial or financial relationships that could be construed as a potential conflict of interest.

Copyright $\odot 2017$ Kapadia and Wyckoff. This is an open-access article distributed under the terms of the Creative Commons Attribution License (CC BY). The use, distribution or reproduction in other forums is permitted, provided the original author(s) or licensor are credited and that the original publication in this journal is cited, in accordance with accepted academic practice. No use, distribution or reproduction is permitted which does not comply with these terms. 